\title{
Left / Write // Hook: A mixed method study of a writing and boxing workshop for survivors of childhood sexual abuse and trauma
}

\author{
Donna Lyon · Shannon Owen - Margaret S. Osborne · Khandis Blake • \\ Bruna Andrades
}

\begin{abstract}
This article investigates how the combination of writing therapy and embodied empowerment, explored through the physical sport of non-contact boxing, can facilitate the recovery journeys of women survivors of childhood sexual abuse (CSA) and their move towards post-traumatic growth. It uses established quantitative psychological measurements and qualitative analytical approaches to examine the impact of an eight-week boxing and writing workshop for female survivors of CSA, called Left/Write//Hook (LWH), on participants' recovery journeys. The hypothesis was that the LWH workshops would contribute to participants' recovery and wellbeing. The article reports on the pilot study of the workshops as one aspect of an ongoing research project around LWH which uses concurrent, triangulation mixed methods design to gather and analyze qualitative audio-visual and creative-writing data produced by the women, alongside quantitative psychological assessment data. The findings of qualitative analyses of the participants' creative writing and the quantitative psychological assessments of the impact of the LWH workshops on participants' assertiveness, post-traumatic stress disorder symptoms, wellbeing, depression, anxiety and stress, along with preliminary findings of filmed material are presented and discussed in this article. The findings supported the hypothesis that the LWH workshops helped facilitate participants' recovery journeys and supported their wellbeing. This article offers preliminary support for the argument that the dual approach of written/verbal and embodied creativity can enhance the wellbeing of survivors of sexual abuse and trauma.
\end{abstract}

Keywords: creativity, wellbeing, child sexual abuse, post-traumatic growth, boxing, writing, creative practice research, creative arts, mixed methods

\section{Introduction}

How do you amplify the voice of those who have been silenced and promote the agency of traumatized bodies? This article reports on the findings of a creative arts mixed methods research project called Left/Write//Hook (LWH), which aids women who have experienced childhood sexual abuse and trauma find a connection to their body, mind and spirit through weekly transformative writing and boxing workshops. Written/verbal and embodied creative acts are paired in two contrasting acts of expression; creative writing and non-contact trauma informed boxing to explore how this can assist survivors in moving towards post traumatic growth. The workshop uses a trauma informed framework, emphasizing self-empowerment, personal agency, and self-determination as its grounding principles. A trauma informed framework focuses on promoting the agency of the survivor while ensuring they have the power of choice 
during the process. As Hopper writes (2017, p. 13), "Instead of reinforcing helplessness, guilt, or shame, this process should open new avenues, build supports, and foster hope."

LWH serves to empower women and amplify their voice, firstly by directly targeting survivors to take part and secondly by gently encouraging or giving invitation to the participants to write about their trauma and lived experiences. The intent of the project is creative rather than therapeutic and therefore the writing prompts are imaginative in their approach. At times, the prompts were purposefully designed to speak to common experiences in survivors, such as guilt, shame and low self-esteem. These thematic prompts give participants a broad and imaginative entry point to creatively write whatever they want about or around their trauma. Writing in the workshop can be from the perspective of a third person or a character's point of view, but at the same time it is about women learning how to safely re-claim or re-story their lives. Writing, sharing and listening are key principles in this workshop to help break the silence inherent in childhood sexual abuse and reduce its stigma of shame.

The initial inspiration for the project came from the first author, Lyon, who is herself a survivor of extreme childhood sexual abuse and trauma. She is also a creative arts practitioner, academic and filmmaker, who was drawn to the sport of boxing as a way of getting fit, feeling empowered and releasing anger. In her blog, Lyon (2019) recalls that:

Trauma, sexual assault and violence often leave women feeling numb. At least, that is how it felt for me. I came to the sport of boxing because I began to experience anger that I knew was directly related to my childhood trauma. I thought boxing would be a positive outlet to release these pent-up emotions, but soon discovered that it was about so much more. Breathing, mindfulness, technique and selfawareness are the processes that dominate this sport. Whilst anger can fuel a training session, it quickly dissipates and the interplay between the physical and intellectual begins. There have been many times during my training that I have dissociated or had intense fear come up (related to perpetrator violence and memory) and countless times that I have cried. My trainers, though not traumainformed, have held a safe space for me, encouraging me to keep going and "fight through". Boxing has become a metaphor for my recovery and my life as a survivor. The positive effects that boxing has had on me, in terms of my overall health and well-being, have been phenomenal. I have met many other women like me, and I have a strong desire to share these stories of recovery, empowerment and hope, using the sport of boxing to aid these conversations.

In 2018, Lyon decided to bring together the concomitant acts of boxing and writing in the LWH workshop. During 2018, she ran the workshop twice and then in 2019, gained a level one certification as a boxing coach and sought collaborative and institutional partners within the University of Melbourne to apply creative research and mixed methods to investigate the efficacy of the program for future expansion. Lyon is the facilitator of LWH and partakes in the writing and sharing component of the workshop, situating herself as a co-participant with the survivors. She then leads the participants in a boxing workout session, training them in non-contact boxing, mixed with cardio and high-intensity exercise relevant to this type of sport.

This research project was designed as a pilot study, using a concurrent, triangulation mixed methods design to bring together creative practice through qualitative audio-visual data and creative writing produced by the women, and quantitative psychological research methodologies to document the therapeutic change process of this arts-based intervention. The 
study offers insight into a program that aims to break the silence of sexual abuse survivors and aid them in gaining body awareness, moving away from shame towards empowerment.

In this study, wellbeing is conceptualized as an exemplar of positive mental health in both hedonic and eudaimonic forms (Keyes, 2009), where the practice of self-care, meaning-making and experience of personal agency is socially embedded and facilitated through quality ties with others (Ryff \& Singer, 2008). The role of the body in movement therapy provides a useful context for this research. The bodily dimension in boxing and the embodiment of the personal narratives of the participants is congruent with Gross-Cohen and Eisikovits's research into the role of the body in dance movement therapy and the relationship between bodily movement and kinesthetic awareness (Gross-Cohen \& Eisikovits, 2018). Their study analyzed the experiences of dance movement therapists in relation to their practice. One therapist recounted a personal definition of wellbeing, describing it as something that can be both practiced and created. For this therapist, wellbeing can involve a "constant movement within the self, among all the physical, mental, and functional dimensions" (Gross-Cohen and Eisikovits, 2018, p. 63). This psychological dimension of wellbeing feeds into the importance of making meaning from one's trauma and experiences in a shared group setting.

Meaning-making is an essential component in the recovery of survivors of childhood sexual abuse and their ability to re-claim a sense of self (Anderson \& Hiersteiner, 2008). Wright and Gabriel (2018) draw on the findings of Bogar \& Hulse-Killacky, 2006; Vilencia et al., 2013 and Wright et al., 2007, to assert that "accepting and understanding the impact on survivors' lives and self-structure, changing old self-beliefs and self-views, and restoring congruency are essential components in the recovery from CSA" (p. 664). Further to this, their findings identified eight key themes which were evident in a survivor's experience of meaning-making. One of these, which is of particular importance to the framework of this project, is that of experiencing personal agency. The impact of the research on the survivor's wellbeing is seen through the nonjudgmental practice of self-care (as a flow of practice), meaning-making through writing and connecting with one's own and others' experiences and feelings of agency. These practices are furthered when engaging in boxing as a form of embodied, expressive and empowered movement.

This paper includes a narrative account of LWH and the research undertaken; at times it is a personalised account of Lyon's experiences. Overarchingly, the paper aims to highlight the creative intentions of the project and acknowledge the lived and firsthand experiences of the women and researchers involved. Arising from interdisciplinary collaboration and adopting a feminist perspective it responds to critiques that these aspects have been missing from previous research on related topics (Bordere, 2017). The study offers a holistic and rounded understanding of abuse survivors and their stories of loss of identity, shame and hopelessness. It acknowledges and brings to light the fight of CSA survivors to reclaim their sense of selves.

\section{Literature on Creativity and Trauma Recovery}

Recent research has demonstrated that talking about abuse is vital to healing and recovery (McClain \& Amar, 2013). Studies have also shown that creative expression is a valid and positive self-help tool to aid healing in survivors of childhood sexual abuse (Cross, 2003; MendezNegrete, 2013). journaling and creative writing, for example, have been found to be effective therapeutic tools to reduce post-traumatic symptoms, assisting survivors to find meaning in life (Creely, 2018; Cross, 2003; Meekums, 2005). Writing that uses free association techniques can unlock unconscious thoughts and beliefs about experiences, acting as a cathartic process while 
remaining creative and imaginative (Lourens, 2020). According to Creely (2018), the process of writing encourages "transformation through emotional disclosure and present insight" (p. 24).

In Australia, no initiative has yet used practice-based approaches to address the needs of women who come to physical activity and sporting environments with the lived effects of CSA. The most significant research in this area thus far has been undertaken by Cathy van Ingen, founder of Shape Your Life (SYL). SYL is a boxing program in Toronto, Canada, designed to teach women and transgendered survivors of violence non-impact, recreational boxing. The survivors are encouraged to locate and view anger as healthy aggression and see it as a tool to aid healing and recovery (van Ingen 2011). Although writing practices are not part of SYL, the program has previously created a participant-led arts project in which survivors have produced artwork and stories culminating in an exhibition to examine the positive effects of art and boxing on exploring individual's trauma experiences (van Ingen, 2016).

It is widely recognized within psychology and movement therapy practice that trauma is stored in the body and that dealing effectively with its impact is best done indirectly through divergent routes within the creative and imaginal realm (Van der Kolk, 2014; Naparstek, 2006). Previous studies have explored the healing and recovery processes for survivors of CSA. In particular, studies in the area of dance movement therapy have provided strong evidence to support the idea that creative work (whether writing, drama, painting or dance) combined with conscious body movement are complementary elements serving to improve the wellbeing and post-traumatic growth for trauma survivors (Jorba-Galdos, 2014; Gray, 2001; Winters Fisher, 2019; Ho, 2015; Orkibi, Bar, and Eliakim, 2014; Mills and Daniluk, 2002; Panhofer \& Payne, 2011). The idea that the body "feels, knows and remembers" (Panhofer, 2017, p.6) is explored in the program of $\mathrm{LWH}$, first through creative writing prompts, then through the act of boxing as a tool of outward expression. Traumatic events leave long-term indelible effects on the body, or "kinesthetic marks" (Panhofer, 2017). When survivors engage in creative and imaginal processes that help regulate the nervous system, they are then better equipped to deal with the mental and emotional aspects of their abuse in therapeutic contexts in a more meaningful way (Naparstek, 2004). Although boxing is considered a high-intensity and cardio-driven exercise, it has proven health benefits for people with diverse health conditions (Sanchez-Latra et al., 2020). Its emphasis on directed and focused movement, strength and conditioning can leave participants feeling strong and empowered. Each punch can serve to direct a survivor's power, anger and frustration in a targeted way (van Ingen, 2011).

The SYL program is grounded in the field of sport for development and peace, which is an approach designed to target disadvantaged communities and regions of the world and activate sport for the benefit of society (van Ingen, 2016). SYL was formed from the belief that sport "can make a useful contribution addressing gender-based violence and critiquing power relations and social inequalities" (van Ingen, 2016).

LWH intersects within the fields of sport for development and peace and dance movement therapy; however, it is distinctive in its combination of sport with creative arts as a practice-based model. It embodies healing and recovery processes that speak to theoretical and experiential modes of healing for survivors of CSA. Throughout the LWH program, participants wrestle with the meanings and profundity of the effects of their abuse and trauma experiences through writing, and then physicalize these through boxing to release some of the confusion, shame and negativity that the writing and sharing may have brought up.

Due to the sensitive and often distressing nature of the subject of CSA, scholars have expressed concern that studies that involve CSA survivors as research participants may serve to further traumatize those involved (McClain \& Amar, 2013). However, McClain and Amar (2013) also 
note that there are greater risks in not doing this type of research, as it leaves unchecked shamebased narratives and survivors' voices remain mute. These latter outcomes are harmful and counter-intuitive to promoting post-traumatic growth.

Although LWH is not group therapy, it is well documented that group settings that encourage sharing and listening to other's stories can be beneficial to the process of healing and recovery (Arias \& Johnson, 2013). The research of Henderson and Bateman (2010, p. 79) affirms this, claiming that:

Telling one's story (the 'trauma narrative') and directly facing the grief, anxiety, anger, betrayal and guilt related to the abuse, enables many to cope better with symptoms, memories and other issues such as substance abuse and relationship problems.

Furthermore, Henderson and Bateman (2010, p. 79, citing White \& Epston, 1989), state:

Persons give meaning to their lives and relationships by storying their experience... and in interacting with others in the performance of these stories they are active in shaping their lives and relationships.

LWH creatively builds on aspects of this research through its practice-based model, using writing prompts as stimuli for participants to share aspects of the trauma narrative that each feels comfortable with through a process of automatic writing, in which the writer lets their thoughts flow onto the paper without pause. These narratives are often fractured and may be fragments of experiences, partly due to the unconscious act of writing automatically (without stopping and as a stream of consciousness) and partly due to the severity of abuse in some participants. The creative nature of the project allows the participants to arrive at their own understanding of what their narrative is or could be. This is enhanced through the practice of writing and actively listening to others' stories, which helps to validate their own experiences. This recognition may serve as stimulus for multiple interpretations of past experiences, but importantly leaves a sense of agency with the women. They can choose to engage with a new or evolved narrative, if they want to, in their own time and in their own way (Anderson \& Hiersteiner, 2008).

\section{Aim and Hypothesis}

This article investigates how the combination of writing therapy and embodied empowerment, explored through the physical sport of non-contact boxing, can facilitate the recovery journeys of women survivors of CSA and their move towards post-traumatic growth, by using established quantitative psychological measurements and qualitative analytical approaches to examine the impact of the LWH workshops on participants. The hypothesis was that the LWH workshops would contribute to participants' recovery and wellbeing.

\section{Project Methodology}

The study draws on Pink's (2015) notion of "blended practice", a methodological approach in creative practice research that encourages practitioners to engage with the affordances of various practices and discourses to enrich the project at hand (Oliver 2018; Pink 2015). Our research team comprised researchers from distinct disciplinary backgrounds of creative arts and psychology. This interdisciplinary expertise allowed the project design to deploy different methods at specific stages of the study. The use of qualitative and quantitative approaches within a concurrent 
triangulation mixed methods research design facilitated a more robust exploration of the research questions than the use of one method alone (Creswell \& Plano Clark, 2011). Quantitative methods were used to measure and analyze the impact of the workshops on participants' assertiveness, post-traumatic stress disorder symptoms, wellbeing, depression, anxiety and stress. Participants in the study also prepared written journals as part of their engagement in the LWH program, and a qualitative analysis of these journals was undertaken. Further details about each of these approaches is given below along with supporting theoretical literature.

A third strand of data collection in the form of ethically engaged documentary filmmaking and participant video diaries also took place. Data sources were then triangulated to ensure that robust conclusions could be generated and to support the validity of future iterations of the project (Creswell, 2009). The documentary aspect of the study was impeded somewhat by the onset of the COVID-19 pandemic. A complete analysis of the documentary film materials is still underway; however, audio-visual data generated through video diaries have been used here as part of the mixed methods data triangulation.

\section{Participants}

Women aged between 18 and 65 years who identified as survivors of childhood sexual abuse and trauma were invited to participate in the study. There was no policy of exclusion based on physical health; rather, the training was modified to accommodate varying fitness levels. As this was a pilot study, only a small number of participants were required. Eight women took part, ranging from 27 to 54 years of age. Five of the women identified as part of the LGBTQIA community, as did Lyon, the facilitator. Three of the women were on a national disability scheme, one was a full-time mother and four women held full-time or part-time jobs. All the women disclosed histories of abuse. Across the group, participants reported psychiatric diagnoses including PTSD, major depression, and psychosis, and had received psychological and pharmacological treatments for these conditions prior to the program. Each participant was screened by the facilitator and asked about the tools, services and/or processes they engaged with to self-assess their physical and mental health, based on their current situation. As this was not a formal therapy process (rather a creative one), the criteria for participation were based on ensuring participants who joined the workshop were currently receiving adjunct mental health support or had undergone previous workshops with Lyon. Women were recruited who saw themselves as displayed a sense of self-efficacy in most areas of life and/or who had or were undergoing therapy or counselling. This was in line with the recruitment method outlined by Arias and Johnson (2013), although many of the project's participants still struggled daily with the effects of CSA.

Participants were drawn to the project due to the combination of writing and boxing, with many participants revealing in their journal writings the desire to disclose, to tell their trauma, to make meaning of their lived experience and re-story their narrative.

Flyers were advertised in the boxing gym where the project was being held and at various organizations and cafes in the local area. The project was also actively promoted through social media, a local newspaper and radio station. The advertising material, plain language statement and consent forms were written in simple English, to be easily understood. A Facebook page was created advertising an information night and the project set up a WordPress blog website. These blog entries formed part of Lyon's reflective thinking around the project.

Interested participants attended an information night to learn about the project and were given a plain language statement and consent form, along with an audiovisual release related to the documentary filming. No special provisions were made for participants with low literacy or 
non-English speaking backgrounds as the research design was not targeting these demographics and there was no funding available for translation services. There was no cost for participants to attend the program and all participants were provided with free hand wraps and either used the boxing gloves at the gym or brought along their own. After the second week of the workshop the group moved online due to the COVID-19 pandemic. One participant's childcare duties changed at that point and she was unable to attend the workshops weekly, resulting in her attending less workshops overall.

\section{Workshop design}

The LWH workshops ran weekly for two hours across eight consecutive weeks. The focus of the first hour was on a "feelings check," whereby participants were asked to share how they felt that day and to talk briefly about their week. This was followed by automatic writing for 10-15 minutes based on prompts to stimulate the process. Automatic writing is a free-conscious writing process by which one writes non-stop to a prompt. Sharing of writing was encouraged, but not mandatory. The second hour of the workshop involved boxing techniques and exercise, including partner work, bag work, cardio, and strength-based training skills.

When the workshop moved online after week two, the exercises were adapted to fit this environment and the focus turned to more individualized cardio and strength-based training, with the inclusion of boxing drills. The program followed a similar structure each week, with the beginning and end of the workshop tailored to allow for introductions. The first workshop involved working through a program handbook written by Lyon, that delved into the workshop and its framework in more depth. All participants were provided with a hard copy of this handbook which outlined safety procedures in the event of challenging emotional situations that might occur from participating. The handbook detailed crisis numbers and strategies in the event of an emergency and in the case of participant distress or adverse emotional responses. At the end of every workshop, all participants were asked to think of three self-care strategies to draw upon for that evening (for example, going to bed early, cuddling a toy, reading a book, or having a bath).

Lyon set up a Facebook message group and checked in with the participants on most weeks both individually and as a group to debrief in an informal way. The group connected throughout the week, sometimes sharing funny posts, or sending everyone good wishes. This helped to strengthen social bonds within the group.

As noted earlier, as a survivor of CSA, Lyon became a facilitator-participant, going on her own journey and process through the workshops and alongside the women. This dual role was fundamental to the workshop's success for Lyon and the participants.

The guidelines for the writing aspect of the workshop were listed in the handbook and read aloud at the first workshop. These advised that: reading aloud was optional but encouraged; trigger warnings would be given and there was no censorship; writing exercises were suggestions and starting points for participants' own explorations; feedback is positive and no judgement calls are made about the writing. Because self-empowerment and personal agency were part of the project's value protocols, participants were given freedom of choice as to how much they wanted to be involved in the research process, including filming. For example, if a participant did not want to submit their writing in a week, they were not forced to. If a person didn't want to be filmed or be the focus of filming in a session, then the team would respect that and avoid focusing on them when filming.

\section{Psychological measures}




\section{Assertiveness}

Participants' assertiveness ratings were captured before and after participation in the LWH program (i.e., before the 8-week program commenced, and after it completed). We measured assertiveness using a Single Category Implicit Association Task (SC-IAT). Implicit association tasks are common psychological tasks that measure the degree to which people implicitly associate two concepts (in this case, associations between the self and assertiveness; Blake, Bastian, O'Dean, \& Denson, 2017). To create the implicit assertiveness task, a separate sample of 26 people read a description of the concept of assertiveness then rated 61 traits on assertiveness on a 7-point scale anchored by Very non-assertive and Very assertive. High assertiveness was characterized as an ability to assert and expand one's self, affect one's environment, and perform actions. Low assertiveness was characterized as unassertiveness. The top and bottom eight traits formed the high and low assertiveness words for the SC-IAT and showed significant group differences on assertiveness in a pilot study, $t(25)=7.95, p<0.001, M_{\text {LowAssertiveness }}=2.29, S D=1.18$, $M_{\text {HighAssertiveness }}=5.59, S D=1.52, d=1.48$. The high assertiveness words were: decisive, driven, gogetter, self-aware, persistent, independent, productive, and strong-minded. The low assertiveness words were: dependent, meek, hesitant, apathetic, idle, inactive, unconcerned, and scatterbrained.

Participants categorized these traits with seven words characteristic of the self (me, my, mine, self, myself; and the participant's own first name and nickname [or, if they had no nickname, their name again]). Implicit associations were assessed by asking people to press the same response key for low assertive + self and to press the opposite response key for high assertive + self. These associations were then reversed and the order in which participants performed these trials was counterbalanced. The SC-IAT effect is the difference in response latency between low assertive + self and high assertive + self. We calculated $D$ scores following established guidelines by Greenwald, Nosek, and Banaji (2003), with higher scores indicating stronger associations of the self with assertiveness.

\section{Post-Traumatic Stress Disorder Symptoms}

The presence and severity of Post-Traumatic Stress Disorder (PTSD) symptoms were measured using the PTSD Checklist for DSM-5 (PCL-5; National Center for PTSD, 2016). This is a 20-item self-report measure that is used to quantify and monitor symptoms over time, screen individuals for PTSD, and assists in making a provisional diagnosis of PTSD. It assesses symptoms over the past month on a 5-point Likert scale anchored by Not at all and Extremely. Summing all 20 items (range 0-80) and using a cut-point score of 33 provides a provisional PTSD diagnosis and suggests the patient may benefit from PTSD treatment. The measure demonstrates sound psychometric properties (National Center for PTSD, 2016), with Cronbach @ values in this study of .94 (pre) and .97 (post). Evidence for the PCL for DSM-IV suggests 5 points as a minimum threshold for determining whether an individual has responded to treatment, and 10 points as a minimum threshold for determining clinically meaningful improvement (Clapp et al., 2016).

\section{Wellbeing}

Wellbeing was measured using the Mental Health Continuum Short Form (MHC-SF; Keyes, 2009). The MHC-SF is a 14-item self-report scale that asks participants to indicate on a Likert scale (anchored by Never and Every day) how often they have experienced aspects of wellbeing including hedonic, emotional wellbeing (e.g. "happy"), eudaimonic, social wellbeing (e.g., social integration "that you belonged to a community, like a social group, or your neighbourhood", and social acceptance "that people are basically good"), and psychological wellbeing (e.g., self- 
acceptance "that you liked most parts of your personality", and personal growth "that you had experiences that helped you to grow and become a better person"). Participants received an overall mean wellbeing score from $0-5$, where higher scores indicate greater wellbeing. The MHC-SF has demonstrated moderate test-retest reliability and good convergent and discriminant validity with existing measures (Lamers et al., 2011). Cronbach @ values in this study were .93 (pre) and .96 (post).

\section{Depression, Anxiety and Stress}

The 21-item Depression, Anxiety, and Stress Scale (DASS-21; Lovibond \& Lovibond, 1995) asks participants to rate their experiences of various symptoms of anxiety, depression, and stress on a 4-point Likert scale (anchored by Never and Almost always) over the past week (Lovibond \& Lovibond, 1995). Items for each subscale were summed, providing a total score from 0-21, for each of depression, anxiety, and stress. Converted, full-measure scores are reported in the results. Reliability and validity of the DASS-21 has been well demonstrated (Crawford et al., 2011; Lovibond \& Lovibond, 1995). Pre and post Cronbach @ values for each subscale in this study were depression: .96, .95; anxiety: .82, .93; and stress: .92, .91.

\section{Results of the Psychological Analyses Assertiveness}

A repeated-measures ANCOVA determined the effect of the program on implicit assertiveness over time. Because assertiveness is positively associated with age and we expected program effects may be dose-dependent, we controlled for the effect of age and program compliance on implicit assertiveness over time. There was a significant effect of time, $F(1,5)=39.52, p=.001$, partial eta squared $=.89$, but it was qualified by a very large time $\times$ age and a very large time $\times$ participation interaction, $F(1,5)=17.05, p=.009$, partial eta squared $=.77$, and $F(1,5)=36.95, p=$ .002 , partial eta squared $=.88$ respectfully. A scatterplot of these interactions indicated that implicit assertiveness increased as a linear function of program compliance $\left(R^{2}=.52\right)$ and age $\left(R^{2}\right.$ $=.08$ ), with the largest effects due to compliance. Indeed, as shown in Figure 1, 52\% of the variance in implicit assertiveness over time was due to compliance. This analysis shows that the program was most effective at raising implicit assertiveness for those who complied with the program and for those who were older. 


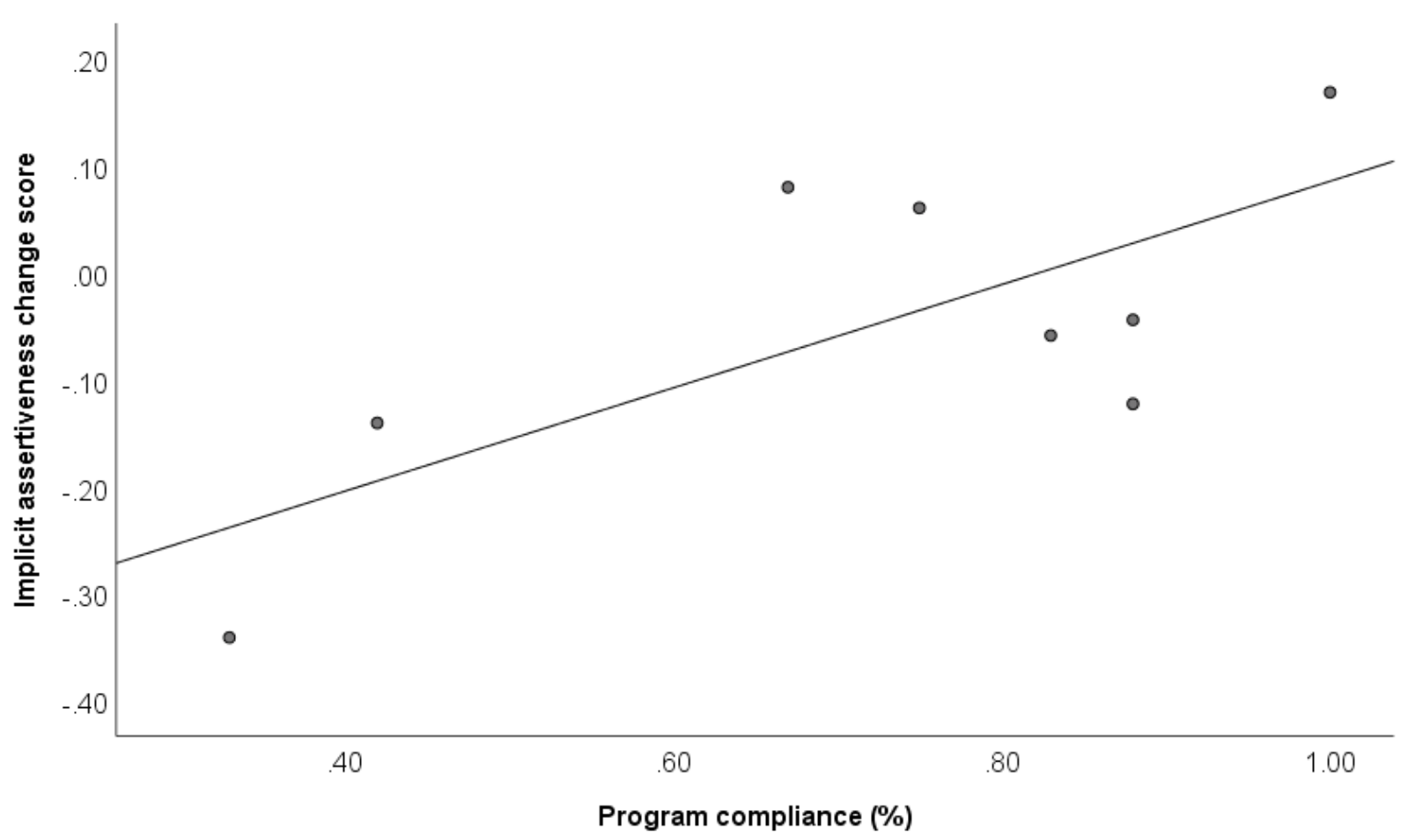

Figure 1. The effect of LWH program compliance on implicit assertiveness change scores over time.

Note: Higher scores indicate an increase in implicit assertiveness over time (i.e., before versus after participation in the LWH program).

\section{Post-Traumatic Stress Disorder Symptoms}

A significant reduction in severity of PTSD symptoms was observed from pre-program $(M=$ $45.63, S D=16.47)$ to post-program $(M=36.00, S D=17.74), t(7)=-2.89, p=.023,95 \% \mathrm{CI}[1.75$, 17.50], Cohen's $d_{z}=1.022$. The CL effect size indicates that after controlling for individual differences, the likelihood that a person scores lower at post-program than pre-program is $85 \%$. The magnitude of reduced mean total score across the program also suggests that the participants achieved clinically meaningful improvement in the PTSD symptomatology at the completion of the 8-week program.

\section{Wellbeing}

There was a significant improvement in overall wellbeing measured by the MHC-SF from preprogram $(M=2.27, S D=0.91)$ to post-program $(M=2.74, S D=1.05), t(7)=2.81, p=0.026,95 \% \mathrm{CI}$ $[0.08,0.87]$, Cohen's $d_{z}=0.99$. The CL effect size indicates that after controlling for individual differences, the likelihood that a person scores higher at post-program than pre-program is $84 \%$. In respect of the Likert scale, the change in mean scores indicates that the frequency with which the women experienced qualities of emotional and eudaimonic wellbeing increased from once a week (2) towards 2-3 times a week (3).

\section{Depression, Anxiety and Stress}

Scores for depression, anxiety and stress all showed a reduction from pre- to post-program: depression (Pre $M=19.25, S D=11.11$; Post $M=16.25, S D=12.30$ ); anxiety (Pre $M=16.00, S D=$ 9.01; Post $M=13.00, S D=10.69$ ); and stress (Pre $M=23.25$, $S D=11.00$; Post $M=18.25, S D=9.71$ ). Although mean score reductions were not statistically significant, reductions were observed in 
symptom severity categories for anxiety (Pre: Severe to Post: Moderate) and stress (Pre: Moderate to Post: Mild). The reduction in depression scores remained in the Moderate range.

\section{Reflective Journal Writing}

Each week workshop participants were presented with a choice of creative prompts to inspire their journal writing. The prompts were selected by Lyon from Jen Cross's Writing Ourselves Whole (2017) and her online e-book Survivors Write (n.d.). These resources offer a framework and writing prompts for use in writing groups for survivors. Prompts pertaining especially to the themes of abuse, healing, recovery, and boxing were chosen. After the COVID-19 pandemic forced the workshops online, other prompts were also included which pertained to isolation and 'the virus'. The theme of isolation resonated for Lyon not only because of its relevance to the COVID-19 pandemic but also because of its relevance to CSA and adult post-traumatic growth. Different prompts were used each week; these are shown in Table 1. Lyon was aware that the writing might bring up experiences and emotions that could be distressing to participants. Crying, tears and emotion were viewed as progress and as evidence of a healing journey, rather than something negative to be feared.

Table 1: Weekly journal-writing stimuli for LWH workshop participants

\begin{tabular}{|c|c|}
\hline Week 1 & $\begin{array}{l}\text { 1. I am here because... } \\
\text { 2. Let me tell you why I am doing this... } \\
\text { 3. Being here... } \\
\text { 4. Today... }\end{array}$ \\
\hline Week 2 & $\begin{array}{l}\text { 1. To punch is to... } \\
\text { 2. I connected and... } \\
\text { 3. Hand to cheek. I step, I punch, I... } \\
\text { 4. There is no wonder I... }\end{array}$ \\
\hline Week 3 & $\begin{array}{l}\text { 1. If it hadn't happened I... } \\
\text { 2. Now that we have connected } \\
\text { 3. The virus } \\
\text { 4. Vulnerability }\end{array}$ \\
\hline Week 4 & $\begin{array}{l}\text { 1. My mother is a foot... } \\
\text { 2. Isolation } \\
\text { 3. The virus part } 2 \ldots \\
\text { 4. } \\
\text { Madness and vulnerability }\end{array}$ \\
\hline Week 5 & $\begin{array}{l}\text { 1. Disgust and Shame } \\
\text { 2. Vulnerability part } 2 . \\
\text { 3. Isolation part } 2 . \\
\text { 4. } \\
\text { The virus part } 3 .\end{array}$ \\
\hline Week 6 & $\begin{array}{ll}\text { 1. } & \text { Body } \\
\text { 2. } & \text { Power } \\
\text { 3. } & \text { Mind }\end{array}$ \\
\hline Week 7 & $\begin{array}{ll}\text { 1. } & \text { Healing is... } \\
\text { 2. } & \text { I remember... } \\
\text { 3. } & \text { Recovery... } \\
\text { 4. } & \text { Things I like... }\end{array}$ \\
\hline Week 8 & $\begin{array}{ll}\text { 1. } & \text { The last } 8 \text { weeks... } \\
\text { 2. } & \text { Being believed means... } \\
\text { 3. } & \text { Fighting back means... }\end{array}$ \\
\hline
\end{tabular}


At the completion of the program, participants collated their journal writings and sent them to Lyon, who then shared them with the research team. The written journals were subjected to thematic analysis following the framework outlined by Braun and Clarke (2006). This is a theoretically flexible approach enabling the identification, analysis and reporting of patterns or themes. Journals were originally formatted in Microsoft Word before being transcribed into a Microsoft Excel spreadsheet. In Excel, all pieces of writings were analyzed and categorized into themes. An inductive approach was then used to identify patterns in the data, while holding the research questions of the LWH program in mind.

\section{The Thematic Analysis of the Written Journals}

Fifty-eight journal items were submitted by the women for analysis. Six journal items were not produced because the participant was feeling unwell or had family commitments. The participants' responses provide an understanding of their motivations and expectations for joining the program. The prompt for the first journal was "I am here because...", and a range of motivations were made evident. For example,

Participant 2: I am here because I want to have a shared reality. Madness is not having my story. Not knowing my story. I am here to have a story, beginning, middle and end.

Participant 3: I am here because my mouth is the only weapon I have left, they took everything else from me but never managed to shut me up."

Participant 7: I am here because I want to exist - I want to take up space, and not be some emotional sponge anymore. I want to know my feelings and release them. I want to fix my body and my mind and feel strong. I want to feel strength radiate through me.

Interestingly, the writings from this first prompt appeared in different ways in the journals and seemed to evolve throughout the weeks. From these journals, the thematic analysis identified three main themes: empowerment, connection/disconnection, and validation. These themes express a broader understanding of the feelings of being abused and conflictions around control, along with a sense of autonomy and agency, the (im)possibility of making a choice, and how they were now fighting back.

\section{Theme 1: Empowerment}

Empowerment was one of the most significant themes in the participants' journals. It reflected how the women felt safer, in control of themselves, strong, and how they were fighting back by doing the workshop. The journals tracked a clear improvement in the women's feelings of empowerment as they progressed through the workshop program. For example, Participant 4 wrote in week 2, "If it hadn't happened, I would not have been so triggered that I became 'insane, 'unwell' or whatever the feeling is." ("If it hadn't happened..." was a prompt proposed at the beginning of this week's writing]) In week 5, the same participant wrote, "For some reason I cannot write about positive things like recovery, healing, and the things I like". In the final week of the program, there appeared to be a shift in the participant's sense of agency in her writing: "Also, this week I got followed home by a man from the Ezymart. I called the police." 
Another example of this theme was provided by Participant 2, who wrote in week 1, "I am here because I could pull a blanket over my head, a blanket of solitude, of safety. I am here because I could create a shield around me." In week 8, as a response to the prompt "Fighting back means..." the participant wrote: "Fighting back means here is my hand, the palm of my hand, see it, it is a stop sign". The shift from needing to create a layer of self-protection around themselves to being able to consider moving the body into a stance of affirmative action, suggests an internal "movement" in how the participant perceived their sense of agency.

\section{Theme 2: Connection/Disconnection}

The second theme, Connection/Disconnection, describes how the women were (dis)connecting with themselves and sometimes with each other in the workshop. This relates to the research of dance movement therapist Elizabeth Lynn Gray (2001), who affirms that the overwhelming nature of abuse on the body and mind causes a fragmentation that relates to the human system and causes a separation between the relationship of self and others. Throughout the workshops, it was possible to see changes in how the women were connecting, especially with each other. For example, Participant 2 wrote in week 1, "I am here because I want community. I am sick of the isolation that saved me. I am sick of getting so locked in myself". For this participant, they appeared to move from feeling isolation to experiencing connection, evident in their writing from week 8: "Eight weeks ago we had individual narratives. Now we all have the same story."

Regarding inner (dis)connection and fragmentation, the journals showed an improvement in how the women were developing a relationship to their trauma narratives. For example, Participant 7 wrote in week 2, "I feel responsible and disconnected. My body, my mind and soul were separated and still struggle to reassemble". In week 8 , this survivor wrote, "I feel a sense of connection - connection to myself, to my centre, to my story, to my writing, my body". Similarly, Participant 8 wrote in week 5, "I feel discoloured, filthy, so dirty dirty dirty". Three weeks later, this participant wrote, "I still remember everything, it's still deeply saddening, but it doesn't feel like it's inside me anymore, like a rock in my guts. It feels like things I know, things I can talk about, but it's a narrative that I can control rather than the other way around". This suggests the feelings of shame so inherent in a survivor's experience had moved from an inner sense of being to something that could now be located outside of the "self".

\section{Validation}

The third theme spoke to how the women felt their stories were validated, and revealed how their need to be heard shifted throughout the workshop. For example, Participant 5 wrote in week 4, "I wish I could tell the so-called professionals just to get fucked and listen to what's within". In week 8 , in response to the prompt "Being believed" they wrote that, "Being believed means I have taken back some power. It means I can finally feel freer". Another example was provided by Participant 3 in week 1, who wrote, "I am here because so many have not wanted to know, found it too hard to listen to". In week 8, this participant affirmed the importance of their stories being heard and accepted, writing, "Being believed means everything. It means validation".

Besides the themes already described here, there were other prominent themes noted within the writings which fall outside the scope of this article. They include memories of the abuse and the lack of support received at the time, along with sentiments of fear, anger and vulnerability, and the implications the abuse has had in their ongoing lives. The women also spoke about the experience and positive impact of boxing, and this rich additional detail will require further analysis. 
It is also worth including here the written words of one participant, Khale McHurst, from the final workshop. McHurst's writing offers insight into how the combination of boxing and writing can powerfully release hidden narratives of abuse survivors through the combination of creative writing and boxing. They also illustrate how changes in the qualities of movement experienced (time, weight, flow and space) recall the qualities of movement proposed by dance movement therapist Rudolf Laban (Laban \& McCaw, 2011). McHurst stated,

It's been such a jarring experience each week to get so deeply entrenched in our collective trauma, to hear each other and cry for one another, then immediately exorcise the sadness from my body. It feels like as we share our secrets, I can feel the hook-like feet of depression trying to grapple onto me, trying to take hold. But before they get a chance to really dig in, I'm up, I'm moving, I'm too fast, you can't catch me, I'll run, I'll punch, there's no way you can get your hooks into me.

By the time we've completed the hour of boxing I'm exhausted, but the sadness, the trauma, feels so much farther away than it did at the start. I still remember everything, it's still deeply saddening, but it doesn't feel like it's inside me anymore, like a rock in my guts. It feels like things I know, things I can talk about, but it's a narrative that I can control rather than the other way around. I feel more like my body is something useful, something that serves me, protects me, rather than something that just makes me a target for abuse. I feel less angry at my body for being female, and more thankful to it for being capable.

\section{Documentary Filmmaking}

The documentary filming forms part of practice-led creative research. It is an iterative and emergent creative collaboration. Drawing on Thomas's (2012) framework of ethically engaged documentary practice it intends to empower the participants through a collaborative sharing of their experiences.

Observational documentary film recordings of the first two sessions were undertaken. Here the filming does not actively intervene in the workshop, instead the camera is positioned as an onlooker observing the workshop. The COVID-19 pandemic resulted in the workshop sessions moving on-line from Weeks 3-8. These were audio-visually documented via screen recordings. Participants were also invited to record video diaries. These participatory video experimentations were an open, creative invitation for the participants to record themselves and/or their surroundings at moments they saw fit during the program. In the absence of weekly observational filming of on-site workshops, these participatory videos became a central element of the documentary aspect of this pilot study.

While a discussion of the broader documentary project falls outside the scope this paper, preliminary review of the documentary component provides evidence to support improved wellbeing amongst participants. Central to these findings is that all participants are interested in continuing to participate in the documentary filmmaking aspect of the project. This is extremely significant given the shame associated with CSA. As Lyon notes, allowing a camera to bear witness to this act of "coming out" as a survivor requires incredible courage. For most participants, LWH is the first time they have shared their experiences of CSA in a group setting. Here personal agency is demonstrated by an active desire to make meaning of their trauma experiences and to share this with a wider public through participation in the documentary filmmaking process. 
Six of the eight participants contributed video diaries. These formed part of an autoethnographic process that shone light on the experiences and meanings of CSA survivors and their everyday lives and served to track the contributors' emotional journeys across the eight weeks. These provide interesting first-person accounts of participants' wellbeing at various stages of the program. The video diaries echoed the key themes of empowerment, connection/disconnection and validation identified in the thematic analysis of journals as the camera became a diarizing tool for recording insight into one's own healing process and pursuit of recovery.

For one participant being filmed was a trigger directly associated with her trauma narrative. Despite this, she engaged in the observational filming of the first two sessions and the recording of video diaries across the eight weeks. In her first video diary the anxiety is palpable as she describes the mixed emotions of being filmed in a safe space and a pride in her ability to position herself in front of the camera for a video diary. By week eight she is noticeably more comfortable in front of the camera and uses the video diary to reflect on the intensity of participating in the program amidst the COVID-19 pandemic and the ways in which the program has inspired and validated her experiences. The video diaries thus offer first-person accounts that shed light on participants' unique stories but also reveal a shared experience of community, connection, and reclamation of self because of participating in LWH. This supports the findings of enhanced wellbeing noted in analysis of the other data sets.

\section{Discussion}

The quantitative psychological measures and the thematic analysis of the participants' written journals provided evidence which supports the hypothesis that the combined acts of creative writing and boxing assist female survivors of CSA in their journey towards recovery and wellbeing. The LWH workshops created a space for the women to disclose their abuse without judgement, offering them opportunities to make meaning out of their trauma, and to re-story their experiences through creative writing and embodied sporting activities. These findings support those of Graham, Powell and Karam (2011) who argued that group participation with fellow survivors increases support for survivors and reduces feelings of isolation, stigma, and shame. While previous studies have given focus to CSA survivor stories (Anderson \& Hiersteiner, 2008; Spermon et al., 2013), the combination of creative somatic and cognitive activities in the LWH program provided a new avenue for understanding the potential pathways towards recovery and wellbeing for participants. As Panhofer (2017) suggested, from the perspective of dance movement therapy, dealing only with the verbal in a therapeutic context omits the experiences stored as memories in the body, and the findings of the present study illustrate how the combination of writing and boxing in the LWH workshops supported a move from implicit to explicit ways of knowing. Further research in the field of dance movement therapy could advantage the program and afford new opportunities for exploring how movement and kinesthetic consciousness can support the move towards post-traumatic growth for female survivors of CSA.

The thematic analysis of participants' written journals identified crucial changes in the way the participants experienced their connection with themselves and with the other women in the group. These transformations centered on the concepts of empowerment, connection/disconnection and validation, building on previous research conducted into the Shape Your Life Program and its participatory arts project (van Ingen, 2016). The validation of the participants' experiences, especially regarding feelings around empowerment, were enhanced after eight weeks. The participants' writings are rich and diverse, and they have 
functioned in this article as a basis for enriching and complementing the psychological data collected concerning a range of wellbeing-related variables. However, both the writing and documentary filming data explore memories of the abuse and its enduring impact in adulthood, which warrant further analysis that goes beyond the scope of the current publication but is currently in progress. A published volume of the writings produced during the program is also anticipated.

The quantitative analysis indicated that the creative acts of boxing and writing improved women's experience of their own assertiveness over time, with an important caveat. For those whose compliance with the program was low, no increase in assertiveness was seen. Conversely, the self-rated assertiveness of some of these participants reduced after poorly added participation in the program. Given the small sample size of this pilot study, these results need replication with larger samples. Nevertheless, it is promising that quantitative, implicit measures-ones that are difficult for participants to fake and thus generally reliable-suggest that strongly compliant participation in the LWH program improves psychological assertiveness among CSA survivors.

Encouragingly, the women demonstrated predicted improvements in PTSD symptoms, wellbeing, and general symptoms of depression, anxiety, and stress across the program. The magnitude of reduction in PCL-5 scores confirms that the LWH program enabled the women to achieve a significant, clinically meaningful improvement in their PTSD symptoms. The wellbeing measure confirmed the experience of personal growth evidenced in the qualitative data. Notably, the women reported more frequent experiences of satisfaction (emotional wellbeing), and more positive functioning through social contribution, social growth (feeling like society was a good place, or becoming a better place for all people), warm, trusting and positive relationships with others, and that their life had a sense of direction and meaning. Again, despite the small sample size, these are powerful indicators of the potential of the LWH program to enable CSA survivors to heal and flourish.

\section{Conclusion}

This pilot study investigated how the combination of writing therapy and embodied empowerment, explored through the physical sport of non-contact boxing, can facilitate the recovery journeys of women survivors of CSA and their move towards post-traumatic growth. It used established quantitative psychological measurements and qualitative analytical approaches to examine the impact of the LWH workshops on participants' wellbeing, and found that the workshops did support the wellbeing of participants and their recovery journeys across a range of variables.

Previous studies have called on research that gives primacy to the voice of survivors, so that their experiences are not mediated through the lens of therapists, researchers, or other professionals (Arias \& Johnson, 2013). That LWH is conceived and facilitated by a survivor of CSA is central to the success of the program and a fundamental component of this study. At the conclusion of the initial eight-week program, the participants made clear their desire to continue, and after a short break the program was reinstated online. At the time of publication of this article, the program continues to operate in eight-week blocks. The resumption of face-to-face activities is also anticipated once distancing restrictions related to the COVID-19 pandemic are sufficiently eased. Further filming and workshops will be scheduled at this time. The findings of this pilot study support the therapeutic potential of the LWH model and indicate that further investigation and research investment is likely to prove beneficial to female survivors of CSA who engage in programs of this kind. 


\section{Acknowledgements}

This research was funded by the Creativity and Wellbeing Hallmark Research Initiative (CAWRI) of the University of Melbourne.

\section{Conflict of interest statement}

The authors report no conflicts of interest.

\section{Authors}

Donna Lyon

The University of Melbourne

\section{Shannon Owen}

The University of Melbourne

Margaret S. Osborne

The University of Melbourne

Khandis Blake

The University of Melbourne and The University of New South Wales

Bruna Andrades

The University of Melbourne

\section{Publishing Timeline}

Received 2 September 2020

Accepted 26 November 2020

Published 17 December 2020

\section{References}

Anderson, K. M., \& Hiersteiner, C. (2008). Recovering from childhood sexual abuse: Is a "Storybook Ending" Possible? The American Journal of Family Therapy, 36(5), 413-424. https://doi.org/10.1080/01926180701804592

Arias, B. J., \& Johnson, C. V. (2013). Treatment of childhood sexual abuse survivors: Voices of healing and recovery from childhood sexual abuse. Journal of Child Sexual Abuse, 22, 822-841. https://doi.org/10.1080/10538712.2013.83066

Blake, K. R., Bastian, B., O'Dean, S. M., \& Denson, T. F. (2017). High estradiol and low progesterone are associated with high assertiveness in women. Psychoneuroendocrinology, 75, 91-99. https://doi.org/10.1016/j.psyneuen.2016.10.008

Bogar, C. B., \& Hulse-Killacky, D. (2006). Resiliency determinants and resiliency processes among female adult survivors of childhood sexual abuse. Journal of Counseling $\mathcal{E}$ Development, 84(3), 318327. https://doi.org/10.1002/j.1556-6678.2006.tb00411.x

Bordere, T. (2017). Disenfranchisement and ambiguity in the face of loss: The suffocated grief of sexual assault survivors. Family Relations, 66(1), 29-45. https://doi.org/10.1111/fare.12231

Braun, V., \& Clarke, V. (2006). Using thematic analysis in psychology. Qualitative Research in Psychology, 3(2), 77-101. https://doi.org/10.1191/1478088706qp063oa

Clapp, J. D., Kemp, J. J., Cox, K. S., \& Tuerk, P. W. (2016). Patterns of change in response to prolonged exposure: Implications for treatment outcome. Depression and Anxiety, 33(9), 807-815. https://doi.org /10.1002/da.22534

Crawford, J., Cayley, C., Lovibond, P. F., Wilson, P. H., \& Hartley, C. (2011). Percentile norms and accompanying interval estimates from an Australian general adult population sample for self-report 
mood scales (BAI, BDI, CRSD, CES-D, DASS, DASS-21, STAI-X, STAI-Y, SRDS, and SRAS). Australian Psychologist, 46, 3-14. https://doi.org/10.1111/j.1742-9544.2010.00003.x

Creely, C. (2018). The efficacy of journal writing in assisting survivors of sexual trauma towards post-traumatic growth. [MA thesis, Lesley University. Expressive Therapies]. Capstone Theses. https://digitalcommons.lesley.edu/expressive_theses/65/

Creswell, J. W. (2009). Research design: Qualitative, quantitative, and mixed methods approaches (3rd ed). SAGE Publications.

Creswell, J. W., \& Plano Clark, V. L. (2018). Designing and conducting mixed methods research (3rd, international student ed.). Sage.

Cross, J. (n.d.). Survivors write: Writing practice for personal and community transformation. http://www.writingourselveswhole.org/Images/WritingWhole-SurvivorsWrite(free_ebook).pdf

Cross, J. (2017). Writing ourselves whole: Restorying our lives. Mango.

Graham, L., Powell, R., \& Karam, A. (2011). (publication). The Power of Social Connection: Developing and Coordinating Sustainable Support Group Programs for Survivors of Sexual Violence. North Carolina: NCCASA and Orange County Rape Crisis Center.

Gray, A. E. L. (2001). The body remembers: Dance/movement therapy with an adult survivor of torture. American Journal of Dance Therapy, 23(1), 29-43. https://doi.org/10.1023/A:1010780306585

B Greenwald A.G., Nosek. A., \& Banaji, M. R.. (2003) Understanding and using the Implicit Association Test: I. An improved scoring algorithm. Journal of Personality and Social Psychology, 85(2): 197-216. https://doi.org/10.1037/0022-3514.85.2.197.

Gross-Cohen, I., \& Eisikovits, Z. (2018). "My body was telling me the direction:" The bodily dimension in the dance/movement therapists' working experiences. The Arts in Psychotherapy, 61, 57-65. https://doi.org/10.1016/j.aip.2017.12.004

Henderson, C., \& Bateman, J. (2010). Reframing responses stage 11: Supporting women survivors of child abuse. an information resource guide and workbook for community managed organisations. Mental Health Coordinating Council.

Ho, R. T. H. (2015). A place and space to survive: A dance/movement therapy program for childhood sexual abuse survivors. The Arts in Psychotherapy, 46, 9-16. https://doi.org/10.1016/j.aip.2015.09.004

Hopper, E. K. (2017). Trauma-Informed Psychological Assessment of Human Trafficking Survivors. Women \& Therapy, 40(1-2), 12-30. https://doi.org/10.1080/02703149.2016.1205905

Jorba-Galdos, L. (2014). Creativity and dissociation. Dance/movement therapy interventions for the treatment of compartmentalized dissociation. The Arts in Psychotherapy, 41(5), 467-477. https://doi.org/10.1016/j.aip.2014.09.003

Keyes, C. L. M. (2009). Overview of the Mental Health Continuum Short Form (MHC-SF). Emory University. Laban, R. von, \& McCaw, D. (2011). The Laban sourcebook. Routledge.

Lamers, S. M. A., Westerhof, G. J., Bohlmeijer, E. T., ten Kloster, P. M., \& Keyes, C. L. M.

(2011). Evaluating the psychometric properties of the mental health continuum-short form (MHC-SF). Journal of Clinical Psychology, 67(1), 99-110.

Lourens, H. (2020). Giving voice to my body: Healing through narrating the disabled self. Disability $\mathcal{E}$ Society. https://doi.org/10.1080/09687599.2020.1778445

Lovibond, S. H., \& Lovibond, P. F. (1995). Manual for the Depression Anxiety Stress Scales. University of New South Wales.

Lyon, D. (2019, January 28). How I Came to Boxing [Blog]. Left Write Hook. https://leftwritehook.wordpress.com/2019/01/28/how-i-came-to-boxing/

McClain, N., \& Amar, A. F. (2013). Female survivors of child sexual abuse: Finding voice through research participation. Issues in Mental Health Nursing, 34(7), 482-487. https://doi.org/10.3109/01612840.2013.773110

Mchurst, K. (2020). The Last Eight Weeks. [Workshop]. Left Write Hook.

Meekums, B. (2005). Creative writing as a tool for assessment: Implications for embodied working. The Arts in Psychotherapy, 32(2), 95-105. https://doi.org/10.1016/j.aip.2005.01.004 
Mendez-Negrete, J. (2013). Expressive creativity: Narrative text and creative cultural expressions as a healing praxis. Journal of Creativity in Mental Health, 8(3), 315-325. https://doi.org/10.1080/15401383.2013.821934

Mills, L. J., \& Daniluk, J. C. (2002). Her body speaks: The experience of dance therapy for women survivors of child sexual abuse. Journal of Counseling $\mathcal{E}$ Development, 80(1), 77-85. https://doi.org/10.1002/j.1556-6678.2002.tb00169.x

Naparstek, B. (2006). Invisible heroes: Survivors of trauma and how they heal. Bantam Books.

Oliver, J. (2018). Associations. Melbourne University Press.

Orkibi, H., Bar, N., \& Eliakim, I. (2014). The effect of drama-based group therapy on aspects of mental illness stigma. The Arts in Psychotherapy, 41(5), 458-466. https://doi.org/10.1016/j.aip.2014.08.006

Panhofer, H. (2017). Body memory and its recuperation through movement. In V. Karkou, S. Oliver, \& S. Lycouris (Eds.), The Oxford Handbook of Dance and Wellbeing (pp. 114-128). Oxford University Press. https://doi.org/10.1093/oxfordhb/9780199949298.013.7

Panhofer, H., \& Payne, H. (2011). Languaging the embodied experience. Body, Movement and Dance in Psychotherapy, 6(3), 215-232. https://doi.org/10.1080/17432979.2011.572625

Pink, S. Akama Y. \& participants. (2015). Un/Certainty. http://d-e-futures.com/wpcontent/uploads/2015/01/Un_certainty_smllowres.pdf

Ryff, C. D., \& Singer, B. H. (2008). Know thyself and become what you are: A eudaimonic approach to psychological well-being. Journal of Happiness Studies, 9(1), 13-39. https://doi.org/10.1007/s10902-0069019-0

Sanchez-Lastra, M. A., Ayan, C., Sener, M., \& Cancela, J. M. (2020). The use of adapted boxing as a rehabilitation strategy in people with diverse health conditions: A systematic review. European Journal of Adapted Physical Activity, 13(1), 6-6. https://doi.org/10.5507/euj.2020.004

Spermon, D., Darlington, Y., \& Gibney, P. (2013). Complex posttraumatic stress disorder: Voices of healing. Qualitative Health Research, 23(1), 43-53. https://doi.org/10.1177/1049732312461451

Thomas, S. (2012). Collaboration and ethics in documentary filmmaking - a case study. New Review of Film and Television Studies, 10(3), 332-343. https://doi.org/10.1080/17400309.2012.695979

Van der Kolk, B. A. (2014). The body keeps the score: Mind, brain and body in the transformation of trauma. London Allen Lane, an imprint of Penguin Books.

Van Ingen, C. (2011). Spatialities of Anger: Emotional Geographies in a Boxing Program for Survivors of Violence. Sociology of Sport Journal, 28(2), 171-188. https://doi.org/10.1123/ssj.28.2.171

Van Ingen, C. (2016). Getting lost as a way of knowing: The art of boxing within Shape Your Life. Qualitative Research in Sport, Exercise and Health, 8(5), 472-486. https://doi.org/10.1080/2159676X.2016.1211170

Vilencia, S., Shakespeare-Finch, J., \& Obst, P. (2013). Exploring the process of meaning making in healing and growth after childhood sexual assault: A case study approach. Counselling Psychology Quarterly, 26(1), 39-54. https://doi.org/10.1080/09515070.2012.728074

Winters Fisher, A. F. (2019). Dance/movement therapy \& warrior wellness: A pilot case study. The Arts in Psychotherapy, 62, 52-60. https://doi.org/10.1016/j.aip.2018.11.010

Wright, M.O., Crawford, E., \& Sebastian, K. (2007). Positive resolution of childhood sexual abuse experiences: the role of coping, benefit-finding and meaning-making. Journal Of Family Violence, 22, 597-608. https://doi.org/10.1007/s10896-007-9111-1

Wright, C., \& Gabriel, L. (2018). Perspectives of adult survivors of child sexual abuse: An exploration of the adjustments to self-structure through meaning-making in therapy. Journal of Child Sexual Abuse, 27(6), 663-681. https://doi.org/10.1080/10538712.2018.1496961 